\title{
Modern preschool building: design and construction practice
}

\author{
Natalia Norina ${ }^{1}$, Svetlana Golovina ${ }^{1}$, and Veniamin Norin ${ }^{1, *}$ \\ ${ }^{1}$ Saint Petersburg State University of Architecture and Civil Engineering, 2nd Krasnoarmeyskaya St., \\ 4, St. Petersburg, 190005, Russia
}

\begin{abstract}
The paper presents a comprehensive analysis of the design solution of the building of a preschool educational establishment in the city of Guastalla (Italy) with the aim of the possibility of adapting such a project to the conditions of Russian cities. A set of basic requirements for preschool buildings according to Russian building codes and rules is presented. They are grouped into four main groups: compliance with sanitary- hygienic and psychological requirements, safety, durability, costeffectiveness, good appearance. A detailed analysis of the structural design of buildings based on a glued laminated frame with curved sections is presented from an environmental point of view. The conclusion is made about the inadmissibility of the use of glued laminated frames as a structural element of the preschool buildings. It is emphasized that the preschool building must in a special way satisfy the physiological needs of a small person. If this requirement is not met, no other advantages of the building will make it suitable for a comfortable and safe stay of children. The paper also presents a comparison of the development trends in the architecture of modern preschool buildings in the Russian and foreign practice of design and construction.
\end{abstract}

\section{Introduction}

In 2013, the Committee on Energy Efficiency and Sustainable Development of the Russian Guild of Managers and Developers created a working group of experts on the formation of the Russian energy efficiency system - Green Zoom, which included investors, developers, architects, engineers. In Russia, there is an active accumulation of experience in the implementation of energy-efficient and environmentally friendly technologies. The direct application of Western experience in this matter will not produce a noticeable result; it is necessary to form a set of technologies adapted to Russian realities. Nowadays, a platform has been created for a comprehensive analysis of projects in order to improve their quality, energy efficiency and environmental friendliness. The goal of the development of the Green Zoom system is to create a practical document that will explain and adapt for Russian practice the huge pool of issues on green building that is currently worrying the domestic market. It is obvious that the green construction will develop in Russia, since today, the status of the issue of developing energy efficiency and energy conservation is of concern to

\footnotetext{
*Corresponding author: norinveniamin@yandex.ru
} 
representatives of various levels, (Decree of the President of the Russian Federation No. 889 (2008) "On reducing the energy intensity of the economy" (by 40\%). Decree of the President of the Russian Federation No. 752 (2013) "On reducing greenhouse gas emissions" (by 25\%). A practical tool to fulfill the requirements of Decrees No. 889 and No. 752 in the country's construction industry is the specially created GREEN ZOOM system. The vector in the field of energy efficiency has been set and must be followed.

Particular attention of the Government of the Russian Federation is paid to preschool educational establishments, as an essential part of the social infrastructure, the construction of which is necessary for the development of regions, because "kids are our future!". However, this slogan has never lost its relevance. In Russia, at all times, all the best was given to children and all conditions were always created so that healthy, strong, morally stable, mentally balanced and happy citizens of our country would grow out of small people.

At the Department of Architectural and Construction Structures of the St. Petersburg State University of Architecture and Civil Engineering, structural solutions of foreign, already existing and often unique, buildings and structures are analyzed with a view to their possible adaptation to the Russian conditions. In particular, the project of a kindergarten built in Italy was analyzed [1], which changes the usual notions of modern "children's" architecture.

\subsection{Author of the project}

Famous Italian architect Mario Cucinella, founder of Mario Cucinella Architects. Born in 1960 in Palermo. He studied with Giancarlo De Carlo at the University of Genoa (graduated in 1987), worked in the workshop of Renzo Piano (1987-1992). In 1992, he founded his own workshop Mario Cucinella Architects in Paris, in 1999 he moved it to Bologna.

Mario Cucinella is the author of green building initiatives: he founded the non-profit organization Building Green Futures, the S.O.S. (School of Sustainability) educational institution to train specialists in sustainability.

In 2014, as part of a team led by LAND Milano Srl, the Mario Cucinella Architects workshop won a competition for a project of the park on the Khodynka Field in Moscow. At the beginning of June 2015, a meeting was held in Rome between representatives of the consortium of the "South Coast of Russia", headed by the General Director Falkevich Alexander Genrikhovich, and the architect Mario Cucinella. During the meeting, an agreement was reached on further cooperation on joint activities in the field of environmental design of modern buildings and structures for various purposes.

\subsection{Kindergarten building concept by Mario Cucinella Architects}

The town of Guastalla in northern Italy was quite seriously affected by the earthquake in May 2012. On the site of two destroyed schools, a day care center was built, which changes the usual notions of modern "children's" architecture. A small building with an area of 1400 $\mathrm{m}^{2}$ is designed for 120 children aged 0 to 3 years. It really does not correspond much to the usual image of preschool: no bright colors, cartoon characters, and other "entertainments". Architecture for kids can also be quite serious, but at the same time informative and not boring at all [2].

The building structure is based on wooden ribs (Fig. 1,2,3). The changing dimensions of the "slots" in these planes form a dynamic internal space and determine a strict, thoughtful sequence of training, game and communication zones. The gaps between the structural ribs are covered with glass panels, which ensures close interaction with the environment. 
Moreover, in some places, for example, at the entrance, they are even left open and trees literally grow through the structure, almost completely erasing the already unsteady line between the environment and the interior. There are almost no color accents in the design, which is quickly corrected by the children themselves, whose clothes, as a rule, colorful and bright. But there are a lot of warm, living tree, surfaces that are various in sensation, and other tricks allowing not to entertain the child, but to help him experience the world around him as fully as possible [1].

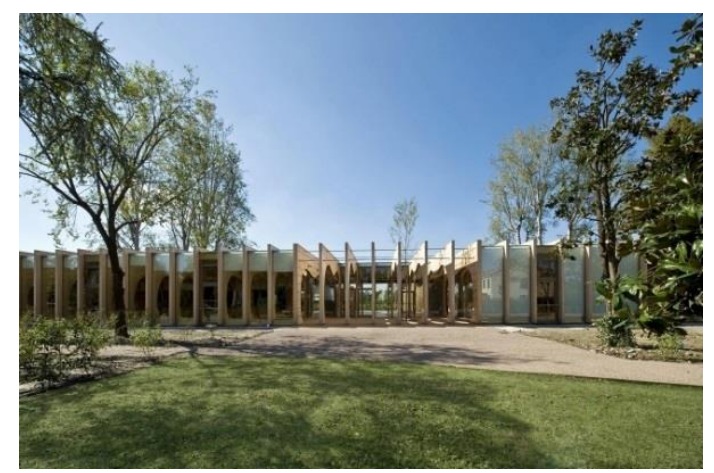

Fig. 1. Exterior of a preschool in the town of Guastalla. (Source: https://www.archdaily.com/775276/nido-dinfanzia-a-guastalla-mario-cucinellaarchitects?ad_name=single-scroll)

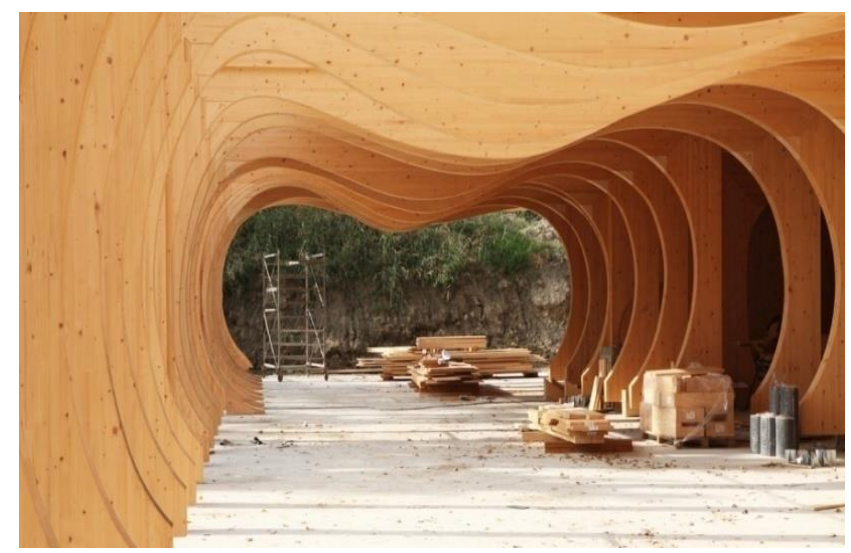

Fig. 2. Installation of glued laminated frames during the construction process. (Source: https://www.archdaily.com/775276/nido-dinfanzia-a-guastalla-mario-cucinellaarchitects?ad_name=single-scroll) 


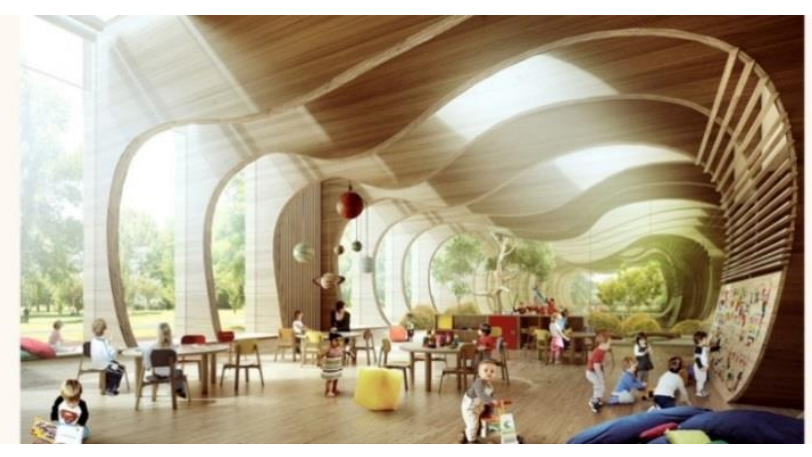

Fig. 3. Interior of a preschool in the town of Guastalla. (Source: https://www.archdaily.com/775276/nido-dinfanzia-a-guastalla-mario-cucinellaarchitects?ad_name=single-scroll)

\section{The method of critical re-evaluation of the constructive solution of the preschool building in the town of Guastalla from the point of view of adapting the project to the conditions of Russia}

\subsection{On the constructive solution of the zero cycle}

The zero cycle of the preschool building in the town of Guastalla is represented by a slab foundation consisting of a continuous, undecked monolithic slab. Typically, such foundations are built with a high level of groundwater, as well as with unevenly compressible, weak soil. Such foundations have rigid spatial reinforcement along the entire bearing plane. In this case, the "plate-basement" system perceives all external loads well, regardless of possible deformations and uneven movements of the base. The slab foundation avoids the costly and often unreliable methods of preventing uneven soil deformation, guaranteeing the reliability of the system for the entire life of the building. Especially effective is the technology of erecting slab foundations in seismic areas, where other structural solutions for protecting the building from soil vibrations require large material and labor costs. In Russia, the technology of slab foundations for low storeys residential and public buildings was developed by the Khabarovsk Institute of Railway Engineers in conjunction with the Far Eastern Construction Research Institute. For the construction of slab foundations, special calculation methods and design principles have been created that make it possible to build a zero cycle of a no-basement building with great reliability and minimal labor and material costs.

\subsection{Glued laminated frames with curved sections. Design features.}

Glued laminated frames with curved sections are widespread in world construction practice, including in Russia.

From the point of view of the balanced bearing capacity, bent glued frames are the most rational. They consist of thin boards glued over the face and usually have a rectangular cross section of constant width and variable height.

Due to the rational constructive solution of the cornice assembly in accordance with the observance of the basic principles of designing rigid frame assemblies, and, consequently, the high reliability of the entire structure, these frames cover significant spans: mass-use constructions up to $24-30 \mathrm{~m}$, unique spans reach $50 \mathrm{~m}$ (Finland) and $74 \mathrm{~m}$ (Germany). At 
the same time, these frames have drawbacks of the technological, and, accordingly, economic order. For bonding, the layer thickness should not exceed $20 \mathrm{~mm}$ (usually 12 - 17 $\mathrm{mm}$ ). Wood waste during sawing and milling significantly increases. For example, wood waste during double-sided fencing along the face of boards with a thickness of $19 \mathrm{~mm}$ makes up 33-38\% of their volume. The large labor costs and the consumption of glue in the production of bent glued frames are caused by the bending of the laminate consisting of many thin layers of boards. In addition, the reduction in the internal dimensions of the building with curved sections of the frames is inevitable.

As for the Russian production of glued laminated frames, the following should be noted. Starting from the 70 s of the last century, numerous examples of failures led to the discreditation of these structures in the territory of the former USSR and even to a regression in their development.

Nowadays, there is a further development of the St. Petersburg design school of V.F.Ivanov, E.N. Kvasnikov, S.A. Dushechkin, E.I. Svetozarova, A.V. Lenyashin and other major specialists of the department "Wooden and metal structures" of the Saint-Petersburg State University of Architecture and Civil Engineering.

New views on the design features and strength assessment of these frames are substantiated and tested by many years of experimental and theoretical research of various glued laminated structures with spans from 3 to $18 \mathrm{~m}$, including the diagnosis of full-scale structures, including unique ones, from Arkhangelsk to Krasnodar and from Vyborg to Abakan. Designed and implemented new glued laminated and glued plywood frames, including with consoles; the reinforced unique arches of the Sports Palace in Arkhangelsk (length - $63 \mathrm{~m}$ ), the dome in Gostilitsy (diameter - $36 \mathrm{~m}$ ) and other objects had no complaints or failures. Some of them have been in operation for over 20 years.

The technological disadvantages of the bent glued laminated frames in Russian production are partially eliminated for low buildings by gluing only racks from thin layers and a rounded transition to the crossbar. Elements of a crossbar made of these frames are obtained by cutting along an oblique line a large-sized block of constant height from thick boards. Thus, a smooth change in the height of the crossbar is easily obtained with almost no glued wood waste.

The main problem of glued laminated structures of mass use in Russia is that, being glued with the same glues at the same enterprises under identical operating conditions, they behave differently. The reasons for the absence or occurrence of defects and failures of glued laminated structures are specific engineering solutions that depend on the level of compliance with the basic laws and design principles, as well as the rationality of taking into account the increased degree of anisotropy of glued wood compared to whole one.

Thus, the analysis of the structural design of buildings based on glued laminated frames with curved sections allowed us to conclude that this constructive solution is very widespread in world construction practice, including in Russia. Moreover, the leading role of Russian scientists in the development of new engineering solutions, calculation methods and manufacturing techniques for modern glued wooden structures should be noted.

However, we have to admit that in no country for the entire period of the existence of this technology has not been built a single building designed for long-term stay of children in it. This is far from accidental, there have always been and are objective reasons for that.

Kindergarten from Mario Cucinella Architects is the first experience in building a facility for long-term stay of children, using bent glued laminated frames.

\subsection{On the quality of the air environment of a preschool}

The most important indicator characterizing comfortable and safe living conditions for children is the required amount of high-quality clean air, i.e. the amount of space in the 
room (the so-called air cube) that must be provided to one person, subject to the organization of effective ventilation. It is determined by two parameters: the area per person and the height of the room. The optimal values of these parameters from the hygienic point of view according to Russian standards are not less than $17.5 \mathrm{~m}^{2}$ per person and height not less than $3 \mathrm{~m}$. Thus, the air volume per person should not be less than $50 \mathrm{~m}^{3}$. These data will be further taken into account when considering the issue of air pollution by chemicals.

Many factors are known that affect the quality of the indoor air environment [3-6]. The main ones are:

- $\quad$ outdoor air and substances entering the room with it,

- compounds released from building structures and from the soil on which the building is built,

- degradation products of polymeric materials used in the manufacture of floors, wall coverings, etc.,

- $\quad$ anthropotoxins - substances released as a result of the vital activity of the human body,

- $\quad$ volatile compounds contained in tap water.

Due to the abundance of pollution sources, hundreds of compounds enter the room air. In 1986, there were more than 300 of only volatile organic (there are also inorganic) compounds found in indoor air in different countries. By 1990, the number of chemical and biological agents found in indoor air exceeded 900. As a result of special studies in the United States, about 1,500 chemical compounds were detected, the content of which in the room was higher than in the outside air (19).

The quality of indoor air is of the greatest importance for children (especially young children), who, on the one hand, are most sensitive to its adverse effects, and on the other hand, spend the greatest time indoors. In young children, many body systems (immune, enzyme, etc.) are characterized by insufficient maturity. This does not allow the body to effectively protect itself from adverse external influences, including the influence of carcinogenic factors.

An important feature of glued laminated frames is that they release various chemicals into the environment (formaldehyde, phenol, acrylates, phthalates, benzene, xylene, toluene, butyl acetate, etc.), and some of these compounds, for example, formaldehyde, have carcinogenic properties.

German researchers found formaldehyde even in the air of children's incubators (for premature babies) treated with a disinfectant. The formaldehyde content in them after 1 hour after processing was 25 parts per million, and only after 28 days it decreased to 0.1 parts per million.

Let us consider formaldehyde, which is present in the air of the room where it comes from glued laminated frames made using formaldehyde glues.

Formaldehyde has a pronounced toxic effect, irritates the mucous membranes of the eyes, throat, upper respiratory tract, causing headache and nausea. Its effect on children is most dangerous (especially under the age of 5 years), because they are most sensitive to its action and are located in the room more than other groups of the population. A group of asthmatic children is especially distinguished.

In Russia, formaldehyde became the object of the first hygiene regulation established for a toxic substance in indoor air: the maximum permissible concentration of formaldehyde was assumed to be $0.01 \mathrm{mg} / \mathrm{m}^{3}$.

It is known that the degree of danger of a carcinogen increases with its concentration. Therefore, when prescribing the maximum permissible concentration of formaldehyde equal to $0.01 \mathrm{mg} / \mathrm{m}^{3}$, Russian scientists are guided by the postulate of L.M. Shabad, who wrote: "Our final goal is, based on the law on the dependence of the carcinogenic effect on 
the dose, to allow contact only with such small doses of carcinogens that could cause malignant neoplasms only after 120-150 years from the onset of exposure. In other words, our goal is to bring cancer out of the longest lifespan of a person".

The above allows us to conclude that it is inadmissible to use glued laminated frames as elements of the open frame of preschool buildings from the point of view of the danger of formaldehyde. It is one thing when the room has a cabinet made of chipboard and the concentration of harmful substances in the air in this case is negligible; another thing is when the walls and ceiling are entirely glued wooden structures. This situation should be considered as representing a threat to the life of a small person.

Perhaps, during the implementation of the project under consideration, glued laminated frames on the basis of good, environmentally friendly glues from Western manufacturers were used. However, the authors of the project are clearly cunning, saying the object is made of natural materials. Wooden glued products differ sharply from natural wood by the presence of glue interlayers between glued boards or planks; interlayers that impede the natural flow of air inside a wooden product, disrupting the circulation of moisture.

\subsection{On the microclimate of a preschool}

According to the project, the building's structural scheme is composed of wooden ribs, the gaps between which are closed by glass panels, which, according to the authors, ensures close interaction with the environment. From our point of view, such a solution cannot be recognized as meeting the most comfortable indoor conditions for preschool children. The authors consider it sufficient to characterize the climate of the area with a set of different "average" temperatures - the average annual, maximum and average minimum temperatures of the coldest and warmest months of the year.

In Russian hygiene science, a different approach has been adopted. It is not enough to know the average temperature of July, the average temperature of January, the average wind speed, the average cloud cover, the average number of clear days, etc. It is equally important to know how many days a year in a given area should be expected with moderate frosts, and how many with strong ones. It is important to know whether days coincide with strong winds with hot or frosty days, whether there are winds in hot weather, or it is calm.

This characteristic of the terrain is provided by complex climatology, which describes the climate not in terms of average conditions of meteorological factors, but by means of the mathematical expectation of the weather in this class. Development of ideas and methods for complex climatology, which is especially important for an architect, builder, engineer, physiologist, etc. is entirely the merit of Russian science and implemented by the works of Academician E. Fedorov, Professor L.A. Chubukov and many other scientists and practitioners.

At a relatively high air temperature (usually above $28{ }^{\circ} \mathrm{C}$ ), the secretory activity of sweat glands is activated in a person at rest. The smallest droplets of sweat emerging on the skin surface merge and moisturize the skin. If the air is relatively dry, i.e. it contains less moisture than it could ultimately contain at a given temperature, then the sweat released evaporates and at the same time cools the surface of the body. If the humidity expressed as a percentage of the maximum saturation is high, then the evaporation of sweat is difficult, and at a very high relative humidity - $80 \%$ or more, it becomes almost impossible. The matter is complicated by the fact that with low air mobility (and in this case, it is a closed room without adequate ventilation), a thin layer of air is created around the body, closely adjacent to the skin. When it is saturated with moisture to the limit, further evaporation of sweat ceases, while the air in the room is still far from saturated with moisture. Light blowing sweeps away this layer, replaces it with another, drier, more moisture-resistant, and this creates a feeling of coolness. 
Therefore, for normal heat transfer, the so-called "physiological deficiency of air saturation" is important. This is the difference between the actual moisture content in the fresh air and the amount that can be contained in the air at a temperature equal to the temperature of the skin. Humidity is important in another way. Warm air with low humidity of less than $40 \%$ has a drying effect on the mucous membranes of the eyes, mouth, upper respiratory tract and can lead to cracks in the mucous membrane and even bleeding from small vessels of the nose.

Speaking about the hygienic assessment of the air, let us dwell on one more point. From our point of view, the authors of the project allow underestimation of the negative role of dust in the room. The applied constructive solution in the form of wooden ribs represents numerous dust collectors. There is a known connection between microbial contamination of the air environment of a room and the content of dust in it, because aerogenic microbes, as a rule, are suspended in the air precisely on dust particles.

In accordance with Russian sanitary standards, the very design of the premises should pay great attention to the maximum elimination of dust formation and possibly easier and more affordable dust removal, "nooks and crannies should not be used, the use of dustforming materials should be excluded, etc.".

In the framework of the paragraph on the microclimate of a preschool, the question of the thermal effect of insolation should be considered.

The thermal effect of insolation is little esteemed by architects and builders. The solar spectrum consists of waves of various lengths from infrared to ultraviolet. Thermal energy is contained mainly in the infrared (invisible) and in the red part of the spectrum. Radiant energy turn into heat only falling onto an opaque screen. Rays, falling on any surface, are not completely converted into heat. Part of the radiation is reflected. The other part is absorbed by the upper layer of the surface. The irradiated upper layer heats up the more, the less heat-permeable the fence. Part of the absorbed heat is returned to the air by radiation and convection. The convection effect is greater, the more mobile the air in contact with the surface. Only part of the heat, usually small one, penetrates the fence and affects the room temperature.

Solar energy varies with latitude, time of year and hour of the day. The amount of direct radiation received by a horizontal surface the greater, the closer to the direct angle of incidence of the beam. Thus, for an area of a given latitude, it is necessary to know the diurnal motion of the sun.

In Russia, the solar meter of D.S. Maslennikov, solar maps of B.A. Dunaev, and solar light meter of L.G. Beridze are used to solve the problems of insolation.

In Russia, in building thermal physics, solar energy is measured in $\mathrm{kcall} / \mathrm{m}^{2} \mathrm{~h}$.

At the suggestion of A.M. Shklover, the effect of solar radiation is estimated by the equivalent temperature that is equal for each individual point in time:

$$
t_{\text {equ }}=\frac{p \cdot I}{\alpha}
$$

where $p$-absorption coefficient equal to $1-A$; here $A$ is the albedo expressed in fractions of a unit;

$I$ - the intensity of solar radiation, expressed in $\mathrm{kcal} / \mathrm{m}^{2} \mathrm{~h}$;

$\alpha$ - heat transfer coefficient depending mainly on wind speed.

The daily average $t_{\text {equ }}$ is calculated using the formula

$$
t_{\text {equ.m } m}=\frac{p \cdot I}{24 \cdot \alpha}
$$

In addition to direct radiation, radiation scattered from the sky and reflected from the underlying surface and surrounding buildings should be taken into account. In the south, in 
a hot, dry climate, reflected radiation is of great importance because at normal values of the albedo of the underlying surface for walls of various orientations, it is $27-50 \%$ of the total. The presence of reflected radiation enhances the overall effect of the total radiation and brings the orientations closer together. Reflected radiation does not have much effect on the closed parts of the fencing, but is very significant for the location and type of sun protection of window openings.

The premises meet the requirements when their temperature regime does not leave the comfort zone.

Based on the results of a lot of practical work done by Russian scientists, the rules of the Russian regulatory documents were formulated for buildings intended for young children, which are under construction in the southern latitudes: "they must have: attic roof, north orientation, night ventilation (windows should close on the day), too wide windows are undesirable".

Windows are the weaker part of building protection in dry areas, where, in addition to direct and diffused, reflected radiation is superimposed on the high average daily air temperature, which cannot be eliminated in any orientation. The reflected radiation does not coincide with the direct one either in time (from sunrise to sunset) or in direction. Only white exterior shutters-blinds are suitable for its reflection. According to the research of N.V. Obolensky, such shutters-blinds detained up to $92.5 \%$ of radiation heat. In particularly hot regions of Russia, shutter-blinds are installed on windows of any orientation, not excluding the north. All kinds of marquises, canopies, etc. are able to protect only from direct radiation, which is enough only with artificial climate control or in moderately hot latitudes.

\subsection{Checking the natural lighting of premises}

Western building sanitary standards, as well as Russian ones, provide for a certain area of windows depending on the floor area of the room [7]. On the other hand, the depth of the room should not exceed more than two and a half times the height from the floor to the window lintel, depending on its shape. In addition to the ratio between the volume of the room and the area of the windows, various factors that play an important role must be taken into account, namely: a) the color of the internal fencing, b) the design of the windows, c) the properties of the glazing, d) the finish of the window, e) the processing of the window frame, e) the color the surroundings of the window; g) the absence of shading on the outside of the window (the most important factor, since all other factors are nullified in the presence of external shading).

In accordance with the norms of natural lighting of premises, the ratio of window area to the area of the room is

- $1 / 6$ - in ordinary cases;

- $1 / 7$, when the angle formed by the horizontal plane and the inclined plane passing through the window sill of the opening and the highest point of the existing or projected opposite facade is between 35 and 45,

- $1 / 8$, when this angle is less than 35

- $1 / 10$ on a hill (above $800 \mathrm{~m}$ ), when this angle is less than 35

The part of the window below $0.5 \mathrm{~m}$ above the floor is not taken into account.

It is necessary to accept an amendment to the area of the room when there is a ledge more than $70 \mathrm{~cm}$ above the windows or if the window lintel is located lower than $2.30 \mathrm{~m}$ from the floor of the room. Exceptions are the windows of the second light. The depth of the room should be no more than 2.5 heights from the floor to the bottom surface of the window lintel. 
If the wall opposite the windows serves to arrange furniture, the depth of the room can be increased by $80 \mathrm{~cm}$.

The lower limit of outdoor lighting under a cloudy sky for the area in question is 4000 $l x$.

The average intensity of illumination of the room corresponds to the dependence

$$
I_{m}=4000 \cdot 0.25 \cdot a \cdot b \cdot c \cdot d \cdot e . . . e t c .
$$

Illumination at floor level:

bright rooms. $150 l x$

medium light rooms....... $(60-150) l x$

dark rooms $60 l x$

Table 1. Checks of the natural lighting of premises

\begin{tabular}{|l|c|l|c|}
\hline Denotation & Coefficients & Denotation & Coefficients \\
\hline Width indicator $L / H=2$ & $a=1$ & $\begin{array}{l}\text { Window width } \\
\text { indicator } l / L=0.5\end{array}$ & $d=0.27$ \\
\hline Depth indicator $P / H=2$ & $b=0.6$ & $\begin{array}{l}\text { Wall reflection } \\
\text { dark color }\end{array}$ & $e=0.6$ \\
\hline $\begin{array}{l}\text { Window height indicator } \\
h / H=1\end{array}$ & $c=1$ & $\begin{array}{l}\text { Ceiling reflection } \\
\text { half dark }\end{array}$ & $f=0.9$ \\
\hline $\begin{array}{l}\text { Slopes and platbands of } \\
\text { wall windows up to 0.1 } \\
m\end{array}$ & $g=0.95$ & $\begin{array}{l}\text { Glass } \\
\text { transparent }\end{array}$ & $n=0.9$ \\
\hline $\begin{array}{l}\text { Window frames } \\
\text { wooden }\end{array}$ & $j=0.65$ & $\begin{array}{l}\text { External shading } \\
\text { related to room } \\
\text { height } \\
0.5\end{array}$ & $q=0.1$ \\
\hline $\begin{array}{l}\text { Curtains } \\
\text { no }\end{array}$ & $m=1$ & $\begin{array}{l}\text { Surrounding } \\
\text { background } \\
\text { light coloured }\end{array}$ & $r=0.95$ \\
\hline
\end{tabular}

It is assumed that the room air is not dusty, the glasses are simple, the coefficients are approximate, intermediate values were obtained by interpolation.

As a result of verification calculations, it was concluded that the lighting at the floor level corresponds to dark rooms and cannot be recommended for a preschool.

\subsection{Psychological aspect}

A very important issue is the spatial requirements for the premises of the kindergarten. This question can be reduced to four interrelated elements - a set of premises, their area, height, proportions. Of course, children at the appropriate age should be able to run freely, which is physiologically necessary for their physical and mental development.

As for height, the experience of psychologists and psychotherapists has shown that corrugated ceilings are uncomfortable in many respects, psychologically perceived as oppressive, overhanging, not providing an aesthetically pleasing perception, and come into conflict with the "freedom reflex" that is natural for a person. A person's negative attitude toward pressing - even when it does not reach such an extent that it violates anthropometric and ergonomic requirements - finds its extreme expression in a special form of mental illness called claustrophobia, i.e. panic fear of pressing rooms [8-16]. 
Not the least role is played by the psychological perception of beauty and the "normality of proportions": it is known that excessively narrow and long rooms have a negative effect on the overall perception of space. The famous rule of the "golden section", intuitively comprehended by the ancient Greeks, basically has a psychological sense of balance, proportionality, beauty. It is psychophysiologically substantiated requirement for architects to strive to comply with this rule when choosing the proportions of residential premises.

Therefore, from our point of view, the constructive solution in the form of glued laminated frames with curved sections in relation to the preschool building is extremely unsuccessful and inappropriate. Mario Cucinella himself says that the interior solution was taken by him from the children's book "Pinocchio". There, the hero of the book falls into the mouth of a whale. Child psychologists recommend, when designing preschools, to adhere to the principle of matching the interior of the preschool and the home interior familiar to the child.

\section{7 $\quad$ Fire prevention precautions}

Wood has a serious drawback - it belongs to the number of combustible materials. Below are the main fire-fighting requirements for buildings of preschool educational establishments based on the Russian State Standards SP 252.1325800.2016 "Buildings of preschool educational establishments", which are absent in the regulatory documents of foreign countries (in particular, Italy).

- preschool premises built into residential buildings should be separated from residential premises by blank fire walls, partitions and ceilings with a fire resistance rating of at least REI 45 or EI 45, respectively, and in buildings of the 1st degree of fire resistance, with type 2 ceilings;

- it is not allowed to install gas equipment in the kitchens of preschools;

- the location and number of evacuation ways and exits should be determined in accordance with Russian State Standards SP 118.13330, SP 1.13130. Each room of the preschool must have at least two separate exits, including from two stairwells from the second and third floors. The width of the opening of the entrance doors of the preschool premises for evacuation should be at least $1.2 \mathrm{~m}$. The width of the corridors along the evacuation ways in the preschool should be at least $1.6 \mathrm{~m}$;

- premises with sleeping places in the preschool buildings should be placed in separate blocks or parts of the building, separated from parts of the building for other purposes (administrative, household, technical, etc.) by fire walls;

\section{Conclusion}

The paper presents a comprehensive analysis of the design solution of the building of a preschool educational establishment in the town of Guastalla (Italy) with the aim of the possibility of adapting such a project to the conditions of the Russian southern cities. A set of basic requirements for preschool buildings according to Russian building codes and rules is considered. They can be combined into four main groups: compliance with sanitaryhygienic and psychological requirements, safety, durability, cost-effectiveness, good appearance. It is emphasized that the building of a kindergarten should in a special way satisfy the physiological and psychological needs of a small person. If this is not observed, then no other advantages of the building will make it suitable for a comfortable and safe stay of children. 
This paper can serve as an example of the analysis of structural solutions of original buildings and structures with the aim of their possible adaptation to specific climatic conditions.

\section{References}

1. M. Cucinella, Kindergarten in Guastalla. https://www.archdaily.com/775276/nidodinfanzia-a-guastalla-mario-cucinella-architects?ad_name=single-scroll

2. American Architectural Foundation. Report from the national summit on school design: A resource for educators and designers. Washington DC. (2006)

3. National Institute of Child Health and Human Development Early Child Care Research Network (NICHD). Characteristics and quality of child care for toddlers and preschoolers. Journal of Applied Developmental Sciences 4, 116 -135 (2000).

4. Josefin Persson, Thanh Wang, Jessika Hagberg. Science of The Total Environment 628-629, 159-168 (2018) https://doi.org/10.1016/j.scitotenv.2018.02.053

5. Allison L.Phillips, Stephanie C.Hammel, Kate Hoffman, Amelia M. Lorenzo, Albert Chen, Thomas F. Webster, Heather M. Stapleton, Environment International 116, 176185 (2018). https://doi.org/10.1016/j.envint.2018.04.013

6. Danica Stankovic, Milan Tanic, Alekandra Kostic, Svetlana Vrecic, Aleksandar Kekovic, Nikola Cekic, Vojislav Nikolic, Svetlana Vrecic, Procedia Engineering 117 $737-750$ https://reader.elsevier.com/reader/sd/pii/S1877705815018573?token=C50CB70D7078 BB345CF0473AA2FC689E87950A903C7D3A38FB55B982C85D5CFC72A5C22C8 DA32699A57CDC438D3FDE13

7. A. Gulbinas, V. Petuhova. E3S Web of Conferences 91, 05014 (2019). https://doi.org/10.1051/e3sconf /2019910

8. J.B. Lyons, Do school facilities really impact a child's education? Council of Education Facility Planners International Issuetrak. Retrieved on 21.02.2010 (2001). www.cefpi.org/pdf/issue14.pdf

9. K. Hunter, University Of Cincinati, Master Of Architecture, Umi Number 1430367 (2005)

10. Robert Gifford, Linda Steg, Joseph P. Reser Environmental Psychology. DOI: $10.1002 / 9781444395150 . c h 18$ https://www.researchgate.net/publication/229909587_Environmental_Psychology

11. D. Stankovic, A. Milojkovic, M. Tanic, , Series Architecture and Civil Engineering, 4(1), 51-57

12. A. Taylor, Linking architecture and education. Sustainable design of learning environments. New Mexico: University of New Mexico Press (2009)

13. G. Ceppi, M. Zini, Children, spaces, relations. Metaproject for an environment for young children Milan: Domus Academy Research Center (2003)

14. Ata Seda, Deniz Aysegul, Akman Berrin, Procedia - Social and Behavioral Sciences 46, 2034 - 2039 (2012 ). doi: 10.1016/j.sbspro.2012.05.424

15. N. Van Note Chism, D.J. Bickford, Improving the environment for learning. The importance of physical space in creating supportive learning environments, 91-99. San Francisco: Jossey-Bass (2002)

16. L. Gee, Human centered design guidelines. Learning spaces, 10.1-10.13. Washington, DC: Educause (2006) 